Supporting Information

\title{
Metal Ion Binding Induces Local Protein Unfolding and Destabilizes Human Carbonic Anhydrase II
}

Kayla D. McConnell, Nicholas C. Fitzkee* and Joseph P. Emerson*

Department of Chemistry, Mississippi State University, Mississippi State, MS 39762

*To whom correspondence should be addressed: nfitzkee@chemistry.msstate.edu, jemerson@chemistry.msstate.edu

\section{Table of Contents}

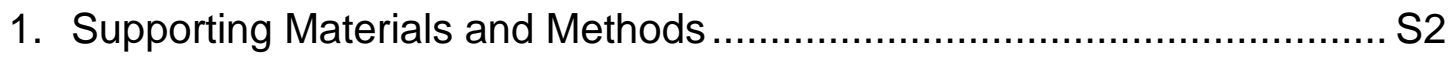

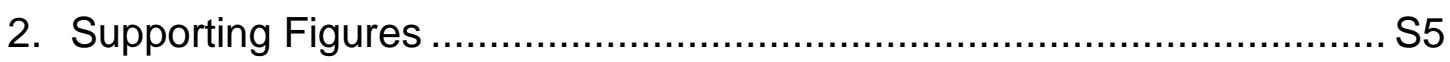

a. ITC thermogram for $\mathrm{Zn}^{2+}$ binding to apo-HCA at $25^{\circ} \mathrm{C} \ldots \ldots \ldots \ldots \ldots . . . . . .55$

b. Free energy, enthalpy, and entropy of metal binding to HCA .......S6

c. Representative fluorescence spectra for denaturation of HCA .....S7

d. Comparison of apparent unfolding parameters HCA ...................S8

e. Copper binding differences in HCA crystal and NMR structures... S9

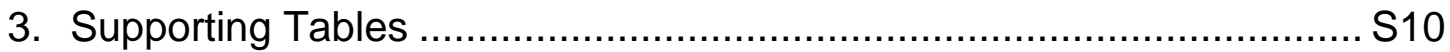

a. Buffer- and $\mathrm{pH}$-corrected thermodynamic binding parameters ...S10

b. Calculation of per-residue folding or unfolding ...........................S11

c. Apparent thermodynamic unfolding parameters for HCA............. S12

4. Supporting Information References ….............................................. 


\section{Supporting Materials and Methods}

\section{Sample Preparation}

The plasmid encoding human carbonic anhydrase II (HCA, pACA) was transformed into E. coli BL21(DE3) cells (Agilent Technologies, Santa Clara, CA, USA). All E. coli cultures containing this plasmid were grown with shaking at $37^{\circ} \mathrm{C}$ in LB media containing $100 \mathrm{mg} / \mathrm{L}$ ampicillin. At an approximate OD600 of 0.6 , cultures were induced with $100 \mathrm{mg} \mathrm{L}^{-1}$ Isopropyl $\beta-\mathrm{d}-1$ thiogalactopyranoside (IPTG) and allowed to grow for another 4 hours. The cells were collected via centrifugation (6,000 rcf for 30 minutes) and lysed by sonication (power level 5, 20\% duty cycle for 6 minutes in a Branson Sonifier 450) in $50 \mathrm{mM}$ Tris buffer (pH 7.4). Streptomycin sulfate was added to the cell lysate to a final concentration of $1 \%(\mathrm{w} / \mathrm{v})$ to precipitate DNA and was allowed to stir at $4{ }^{\circ} \mathrm{C}$ overnight. Cell lystate was clarified by centrifugation $(50,000$ rcf for 45 minutes) and then loaded onto a strong anion exchange column (GE life sciences, HiTrap Q FF). Flow-through fractions containing the protein of interest were collected and the column was regenerated with a $500 \mathrm{mM} \mathrm{NaCl}$ wash. HCA concentrations were determined by UV absorption at $280 \mathrm{~nm}\left(\varepsilon_{280}=54,000 \mathrm{M}^{-1} \mathrm{~cm}^{-1}\right)$. Protein activity was assessed using para-nitrophenyl acetate (pNPA) hydrolysis assays and were performed as previously described. ${ }^{1}$ All assays were performed in the final dialysis buffer at $\mathrm{pH}$ 7.4. A $20 \mu \mathrm{L}$ sample of $20 \mathrm{mM}$ pNPA in acetonitrile was added to $1 \mathrm{~mL}$ of buffer in a disposable cuvette. Up to $20 \mu \mathrm{L}$ of a protein solution was then mixed into the cuvette and the absorption at $404 \mathrm{~nm}$ was monitored for 60 seconds. Activity was calculated based on the conversion of pNPA to $\mathrm{p}$-nitrophenol $\left(\varepsilon_{404}=17,300 \mathrm{M}^{-1} \mathrm{~cm}^{-1}\right)$. Fractions showing good activity were concentrated via an ultrafiltration centrifugal device with a polyethersulfone (PES) membrane with a $10 \mathrm{~K}$ molecular weight cutoff (MWCO). The concentrated fractions were then loaded onto a Sephacryl S-200 size exclusion column (GE Healthcare), which was subjected to an isocratic flow of $50 \mathrm{mM}$ Tris buffer (pH 7.4) with $200 \mathrm{mM}$ $\mathrm{NaCl}$. Fractions showing good activity and displaying a single band on an SDS-page gel were deemed to be pure HCA. To ensure uniformity in metal binding, metals present during the growth and purification steps were then chelated from HCA. Purified HCA was dialyzed overnight against $1 \mathrm{~L}$ of $50 \mathrm{mM}$ Tris buffer containing $50 \mathrm{mM}$ dipicolinic acid (DPA, pH 7.4) as described previously to generate apo-HCA. ${ }^{1-3}$ The purified HCA was then dialyzed against $2 \mathrm{~L}$ of $50 \mathrm{mM}$ Tris buffer (pH 7.4) to remove the DPA and finally dialyzed overnight against $1 \mathrm{~L} 100 \mathrm{mM}$ TES buffer (pH 7.4). For sample preparation described here and all analytical characterization below, no unexpected or unusually high safety hazards were encountered when performing this work.

\section{Isothermal Titration Calorimetry (ITC)}

ITC experiments were carried out at $15^{\circ} \mathrm{C}, 20^{\circ} \mathrm{C}, 25^{\circ} \mathrm{C}, 30^{\circ} \mathrm{C}$ and $35^{\circ} \mathrm{C}$, using a MicroCal VPITC calorimeter. Samples were buffered at $\mathrm{pH} 7.8$ with 50 mM PIPES, ACES, MOPS, or HEPES. A typical experiment consisted of 50-70 $\mu \mathrm{M}$ apoCA titrated with $1.5-2.0 \mathrm{mM} \mathrm{ZnCl}_{2}$ or $\mathrm{CuCl}_{2}$ in matched buffers. All solutions were degassed under vacuum prior to running the experiments. The ITC data were fit as previously described. ${ }^{1,3}$ Data sets were collected in triplicate (or more) and the average and standard error of the mean were reported for fitting parameters. All ITC data shown are the baseline-corrected raw data, along with the integrated, concentration-normalized heat of reaction $(\Delta \mathrm{H})$ versus the molar ratio of metal ion to protein $(n)$. The free energy change term for the experimental data was calculated for each experiment using the equilibrium constant obtained from the best fit $(\mathrm{K})$. Experimental thermodynamic values obtained through ITC are a combination of many different species in equilibria. To determine more accurate thermodynamic 
terms for metal binding, the ITC data was deconvoluted, as described previously, into buffer ionization heats, buffer-metal interaction heats, and protein binding heats. ${ }^{3}$ All reported values have been corrected to reflect the metal-protein interaction alone. $\Delta C_{P}$ values are determined as the best-fit slope of the buffer-corrected $\Delta H$ vs. $T\left(\Delta C_{P}=\partial \Delta H / \partial T\right)$.

\section{Circular Dichroism (CD)}

Apo-, Zn-, CuZn- and CuCu-HCA samples were all prepared by addition of a molar equivalent of each metal to $1 \mu \mathrm{M}$ apo-HCA. For example, for the $\mathrm{CuZn-HCA}$ sample, one equivalent of $\mathrm{ZnCl}_{2}$ was first added to the protein and allowed to equilibrate for $30 \mathrm{~min}$, and then one equivalent of $\mathrm{CuCl}_{2}$ was added and again was allowed to equilibrate for $30 \mathrm{~min}$. The final concentrations in this sample are $1 \mu \mathrm{M}$ each of $\mathrm{CA}, \mathrm{ZnCl}_{2}$ and $\mathrm{CuCl}_{2}$. For the $\mathrm{CuCu}-\mathrm{HCA}$, two equivalents of $\mathrm{CuCl}_{2}$ were added to $\mathrm{CA}$ and allowed to equilibrate for $30 \mathrm{~min}$. Based on thermodynamic parameters from ITC, these conditions should result in more than $95 \%$ of the protein being saturated at each site with the corresponding metal ions. CD studies were conducted using an Olis DSM 20 CD in a 1 $\mathrm{mm}$ pathlength quartz cell at $25^{\circ} \mathrm{C}$. CD Spectra were buffer corrected and the high tension (HT) voltage was monitored and never exceeded $900 \mathrm{~V}$, even at far-UV wavelengths. The spectra were then corrected for concentration and data are shown as molar ellipticity.

\section{Fluorescence Denaturation Studies}

Guanidinium chloride ( $\mathrm{GdmCl}$ ) denaturation studies were performed to further probe the stability of each of the four forms of CA; apo-HCA, Zn-HCA, CuZn-HCA and CuCu-HCA. All fluorescence data were measured by a Horiba FluoroMax 4 spectrofluorometer with a Quantum Peltier-based heated/cooled cuvette holder and Microlab dual syringe auto-titrator $\left(\lambda_{\mathrm{ex}}=280 \mathrm{~nm}, \lambda_{\mathrm{em}}=300-400\right.$ $\mathrm{nm}$ ). A Starna $1 \mathrm{~cm}$ path length quartz cuvette with a small magnetic stir bar was used for mixing. Reported spectra are the average of a series of 5 scans made at 1-nm intervals, 0.1 second signal integration time, and 5.0-nm entrance and exit slit bandpass, which have been corrected relative to an appropriate baseline scan including the buffer and denaturant. Protein concentrations were $0.05 \mu \mathrm{M}$ in $100 \mathrm{~mm}$ TES buffer at a pH of 7.4, and the titrant consisted of approximately 6.0-7.0 $\mathrm{M} \mathrm{GdmCl}$. GdmCl concentrations were determined as previously described via an Abbe refractometer. ${ }^{4}$ The auto-titrator was loaded with $5 \mathrm{ml}$ of $\mathrm{GdmCl}$ and programmed for titration steps starting at $0.1 \mathrm{M}$ and ending at $4.0 \mathrm{M} \mathrm{GdmCl}$. Between titration steps, the sample was equilibrated with mixing for 300 seconds before each spectrum was recorded. Unfolding curves were generated and fit to a two-state unfolding model used to estimate the apparent unfolding $\Delta G_{\text {unf }}^{o}$ and the $m$-value for each HCA sample. ${ }^{5}$ Experiments were repeated in triplicate. Uncertainties in $\Delta G_{u n f}^{o}$ and the $m$-value are reported as the standard deviation from a nonparametric bootstrap resampling simulation of normalized fluorescence intensities $(n=100$ resamples).

\section{Calculation of $\Re^{\text {th }}$}

The theoretical number of residues that fold upon binding $\left(\mathfrak{R}^{t h}\right)$ was calculated according to the method of Spolar and Record. ${ }^{6}$ The calculations are summarized below.

To start, the buffer- and $\mathrm{pH}$-corrected enthalpy $(\Delta H)$ and the standard state Gibbs energy $\left(\Delta G^{\circ}\right)$ are determined from ITC experiments at a single temperature $T$. The enthalpies from several temperatures are collected, and the change in heat capacity $\left(\Delta C_{P}\right)$ is determined from the slope of $\Delta H$ vs. $T$. Then, the entropy at one specific temperature $T_{r e f}$ is calculated as: 


$$
\Delta S\left(T_{\text {ref }}\right)=\frac{\Delta H\left(T_{\text {ref }}\right)-\Delta G^{o}\left(T_{r e f}\right)}{T_{\text {ref }}}
$$

This enthalpy change is assumed to be the sum of a hydrophobic effect term $\left(\Delta S_{H E}\right)$, a rotational-translational entropy loss term $\left(\Delta S_{r t}\right)$, and a protein conformational entropy term $\left(\Delta S_{\text {conf }}\right) . \Delta S_{r t}$ is assumed to be temperature dependent, ${ }^{7}$ and Spolar and Record reason that $\Delta S_{\text {other }}$ is independent of temperature as well: ${ }^{6}$

$$
\Delta S=\Delta S_{H E}+\Delta S_{r t}+\Delta S_{\text {conf }}
$$

Of these terms, the conformational entropy term contains the information about the number of residues that fold upon binding. The $\Delta C_{P}$ determined from calorimetry is used to estimate the temperature $\left(T_{S}\right)$ where the reaction enthalpy is zero $\left(\Delta S_{T_{S}}=0\right)$. This temperature is calculated in the following way:

$$
\begin{gathered}
\Delta S_{T_{S}}-\Delta S_{T_{\text {ref }}}=\Delta C_{P} \ln \left(\frac{T_{S}}{T_{r e f}}\right) \\
0-\Delta S_{T_{r e f}}=\Delta C_{P} \ln \left(\frac{T_{S}}{T_{r e f}}\right) \\
T_{S}=T_{\text {ref }} \exp \left(-\frac{\Delta S_{T_{r e f}}}{\Delta C_{P}}\right)
\end{gathered}
$$

Of the terms in equation (2), $\Delta S_{r t}$ and $\Delta S_{\text {conf }}$ are assumed to be temperature independent over a wide temperature range. $\Delta S_{r t}$ is estimated from statistical thermodynamics considerations and

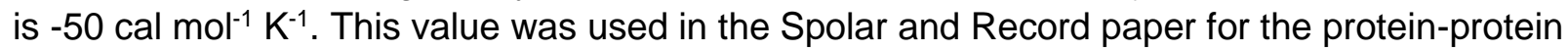
association and has not been adapted for $\mathrm{Cu}^{2+}$ ions. ${ }^{6} \Delta S_{H E}$ is estimated to be

$$
\Delta S_{H E}=1.35 \Delta C_{P} \ln \left(\frac{T}{386}\right)
$$

This equation was originally estimated for globular proteins when the change of surface area is not directly known. Therefore, at $T_{S}$, equation (1) becomes:

$$
\Delta S_{\text {conf }}=-\Delta S_{H E}-\Delta S_{r t}=-1.35 \Delta C_{P} \ln \left(\frac{T_{S}}{386}\right)-\Delta S_{r t}
$$

$\Delta S_{\text {conf }}$ was parameterized by Spolar and Record to yield an average entropy loss per residue of $-5.6 \mathrm{cal} \mathrm{mol}^{-1} \mathrm{~K}^{-1}$. Thus,

$$
\mathfrak{R}^{\text {th }}=\frac{\Delta S_{\text {conf }}}{-5.6 \mathrm{cal} \mathrm{mol}^{-1} \mathrm{~K}^{-1}}
$$

Uncertainties in $-T \Delta S$ and $\Delta C_{P}$ in Table 1 are reported as the standard error of the mean for at least three different ITC experiments. Values of in $\Re^{\text {th }}$ are provided as the mean for $\Re^{\text {th }}$ calculated at the five temperature values from $15-35^{\circ} \mathrm{C}$. The uncertainty in $\Re^{\text {th }}$ is calculated assuming a $\pm 20 \%$ error in the rotational-translational entropy loss $\left(\Delta S_{r t}\right)$ from metal binding (see text). 


\section{Supporting Figures}

\section{Time (min)}
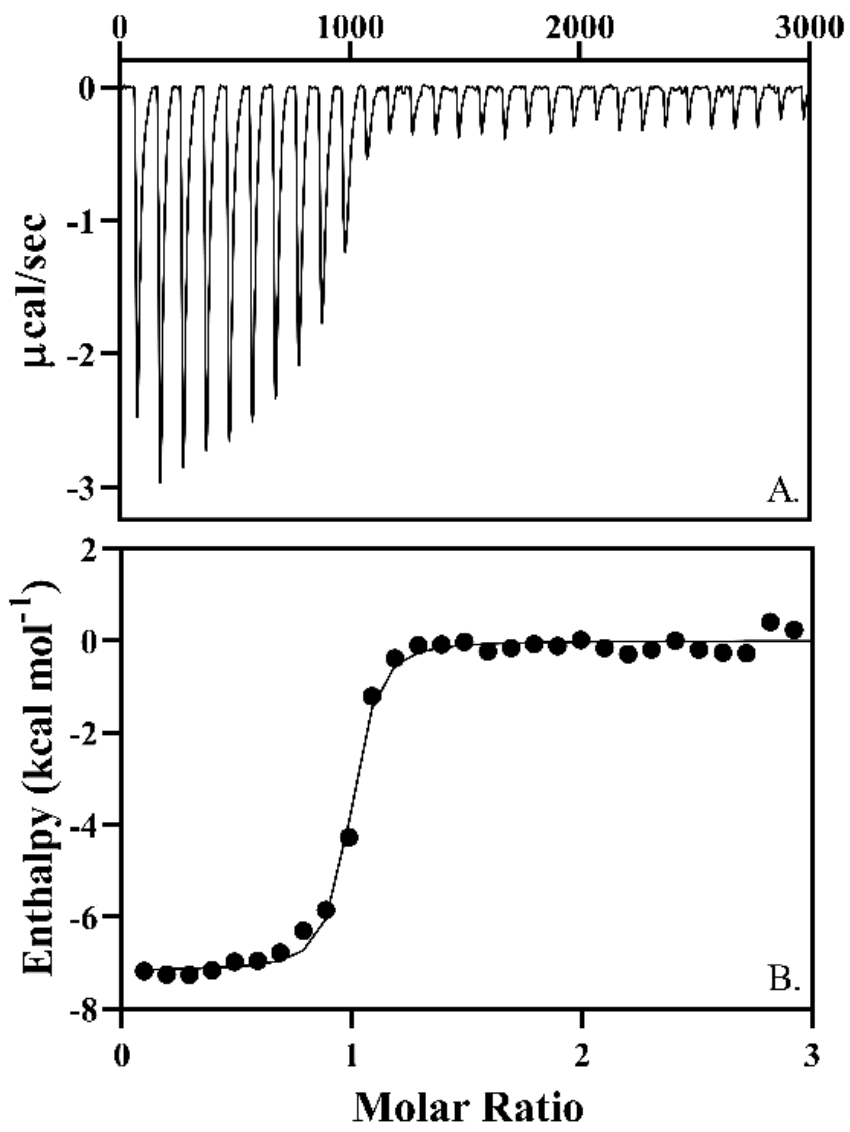

Figure S1. ITC thermogram for $\mathrm{Zn}^{2+}$ binding to apo-HCA at $25^{\circ} \mathrm{C}$. (A.) The raw injection heats for $\mathrm{Zn}^{2+}$ binding to apo-HCA. (B.) The integrated change in enthalpy $(\Delta H)$ from $(\mathrm{A})$, along with the non-linear least squares fit. 

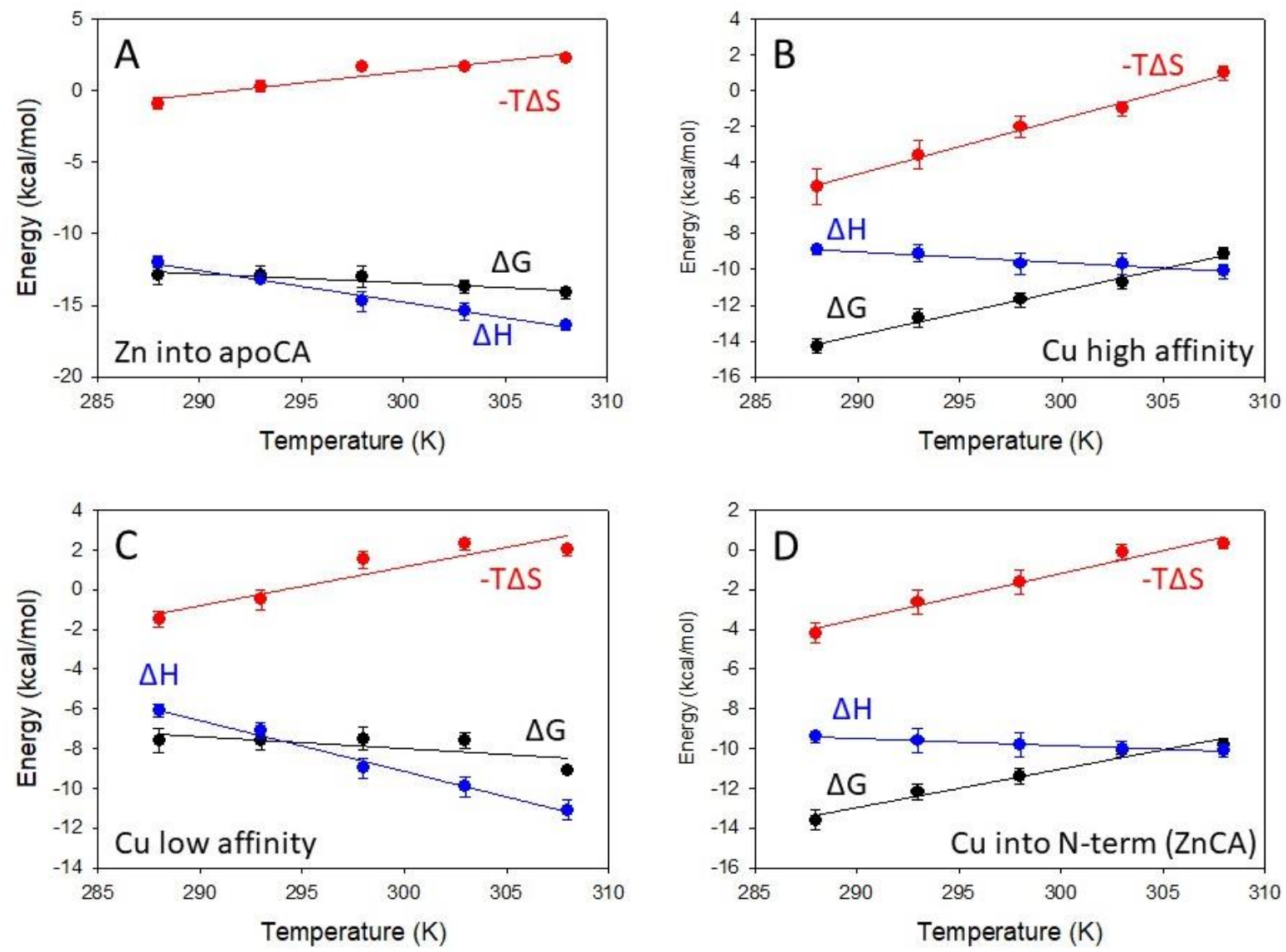

Figure S2. Free energy, enthalpy, and entropy of metal binding to HCA. Energy diagrams associated with the buffer- and $\mathrm{pH}$-corrected thermodynamic values are shown for metal binding to HCA: (A.) Zinc(II) binding to apo-HCA ([Zn]-HCA), (B.) the high affinity (N-terminal) site in copper(II) binding to apo-HCA ([Cu]-HCA), (C.) the low affinity (active site) in copper(II) binding to apo-HCA ([Cu]Cu-HCA), and (D.) copper(II) binding to the ZnCA ([Cu]Zn-HCA). 

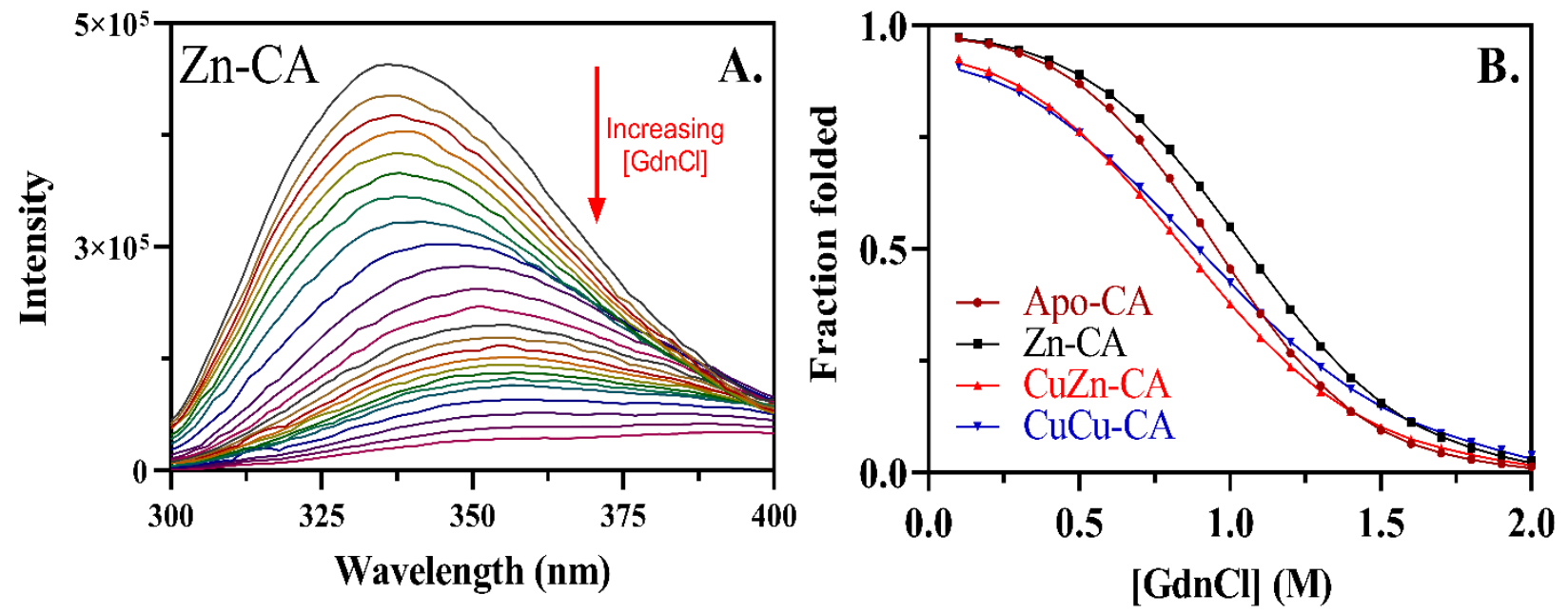

Figure S3. Representative fluorescence spectra for denaturation of HCA. Guandinium chloride $(\mathrm{GdmCl})$ was used to denature apo-HCA, Zn-HCA, CuZn-HCA and CuCu-HCA. (A.) Raw fluorescence spectra at increasing amounts of denaturant, (B.) Calculated protein fraction folded as a function of denaturant concentration. 
A.

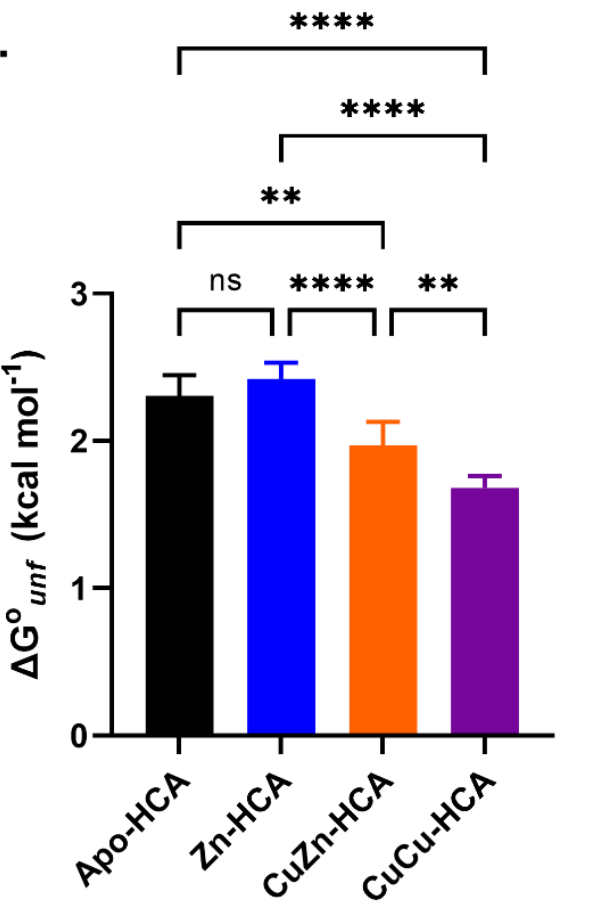

B.

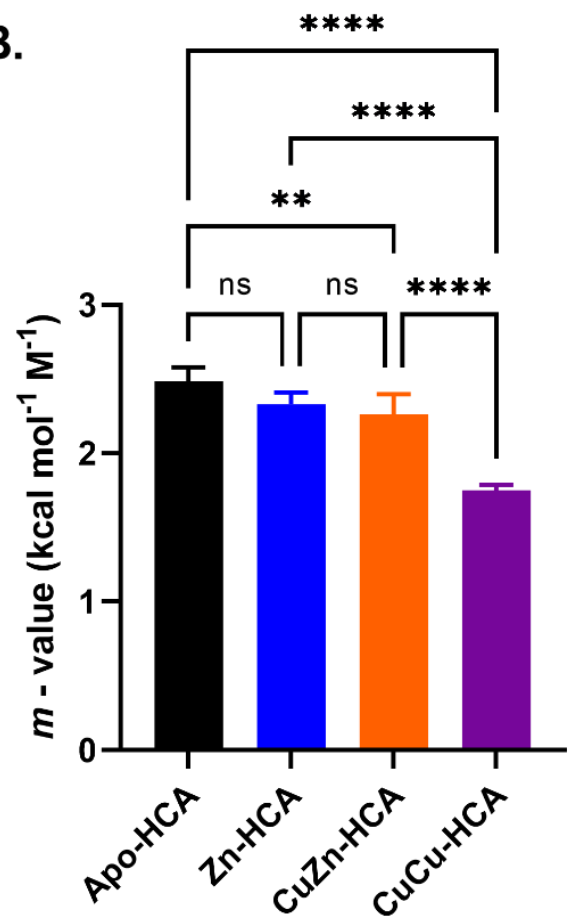

Figure S4. Comparison of apparent thermodynamic unfolding parameters in HCA. (A.) Apparent $\Delta G_{u n f}^{o}$ and (B.) denaturant $m$-values determined from fluorescent fits in Figure S3. Error bars represent the 95\% confidence interval from 100 nonparametric bootstrap resampled datasets from Figure S3. ${ }^{8}$ Statistical significance was determined using one-way ANOVA $\left(\Delta G_{u n f}^{o}: F(3,396)=28.25, p<\right.$ $0.0001 ; m: F(3,396)=46.36, p<0.0001)$, and a multiple-comparisons test was performed using Tukey's honestly significant difference (HSD) post-hoc test. Significance is given by: ns, not significant; ${ }^{*}, p<0.05 ;{ }^{* *}, p<0.01 ;{ }^{* * *}, p<0.001$; ${ }^{* * * \star}, \mathrm{p}<0.0001$. 

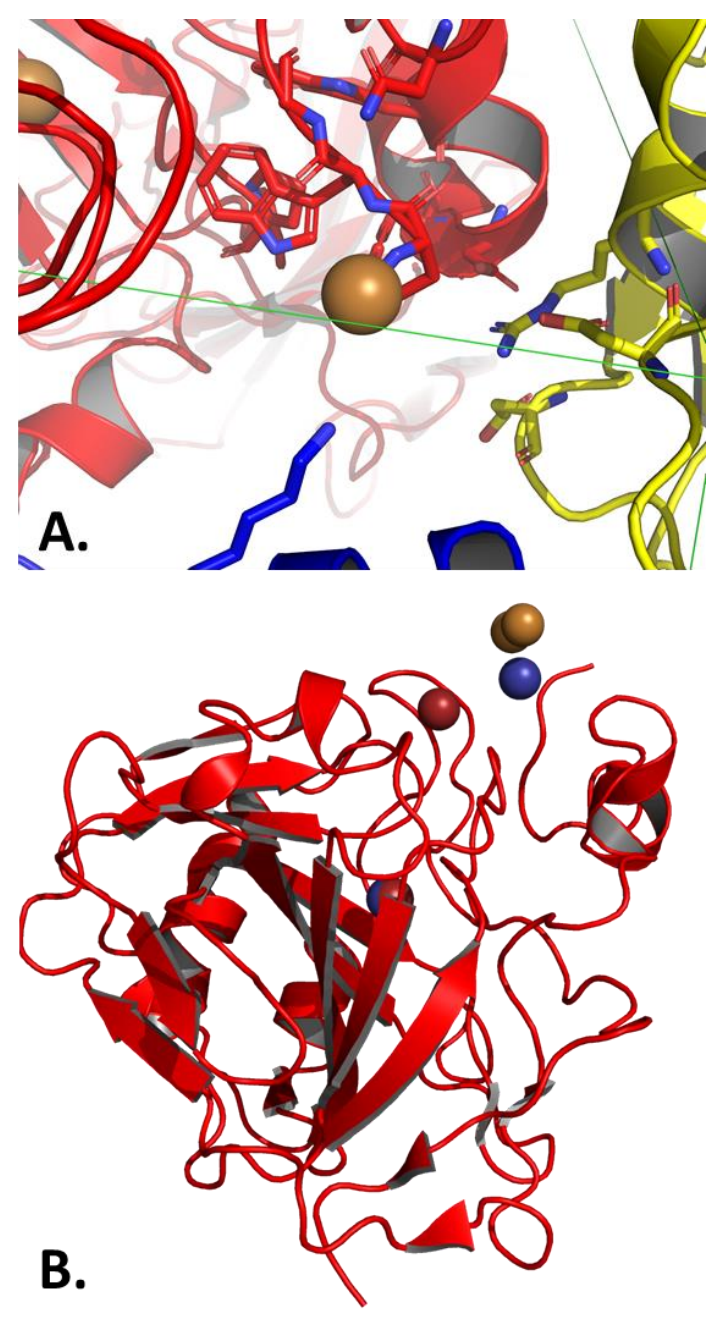

Figure S5. Copper binding differences in HCA crystal and NMR structures. (A.) The Nterminal copper position in PDB 6LVA is close to a unit cell boundary (drawn with green lines), and His 4 makes contacts across this boundary. This suggests possible stabilization of this site. Proteins from different unit cells are colored differently. (B.) N-terminal copper binding shows three different positions for PDB 1RZC (red), ${ }^{9}$ 6LVA (blue), ${ }^{10}$ and the two low-energy minima determined by solution NMR (yellow). ${ }^{3}$ 


\section{Supporting Tables}

Table S1. The $\mathrm{pH}$ and buffer independent thermodynamic values obtained through ITC experiments

\begin{tabular}{|c|c|c|c|c|c|c|}
\hline Titrant & $\begin{array}{c}\text { Protein } \\
\text { Target }\end{array}$ & $\begin{array}{l}\text { Temp } \\
\text { (K) }\end{array}$ & $K_{a}$ & $\begin{array}{c}\Delta G \\
\text { (kcal } / \mathrm{mol})\end{array}$ & $\begin{array}{c}\Delta H \\
\text { (kcal/mol) }\end{array}$ & $\begin{array}{c}-\mathrm{T} \Delta S \\
(\mathrm{kcal} / \mathrm{mol})\end{array}$ \\
\hline \multirow{5}{*}{$\mathrm{Zn}^{2+}$} & \multirow{5}{*}{$\begin{array}{c}\text { Apo-CA } \\
\text { (Active site) }\end{array}$} & 288 & $5.9( \pm 1.2) \times 10^{9}$ & $-12.9 \pm 0.7$ & $-12.0 \pm 0.4$ & $-0.9 \pm 0.4$ \\
\hline & & 293 & $4.4( \pm 0.8) \times 10^{9}$ & $-12.9 \pm 0.6$ & $-13.2 \pm 0.3$ & $0.3 \pm 0.4$ \\
\hline & & 298 & $3.6( \pm 1.0) \times 10^{9}$ & $-13.0 \pm 0.7$ & $-14.7 \pm 0.7$ & $1.7 \pm 0.3$ \\
\hline & & 303 & $7.7( \pm 0.5) \times 10^{9}$ & $-13.7 \pm 0.4$ & $-15.4 \pm 0.6$ & $1.7 \pm 0.2$ \\
\hline & & 308 & $1.0( \pm 0.3) 10^{10}$ & $-14.1 \pm 0.4$ & $-16.4 \pm 0.4$ & $2.3 \pm 0.3$ \\
\hline \multirow{5}{*}{$\mathrm{Cu}^{2+}$} & \multirow{5}{*}{$\begin{array}{c}\text { Apo-CA } \\
\text { (N-terminal } \\
\text { site) }\end{array}$} & 288 & $6.9( \pm 1.3) 10^{10}$ & $-14.3 \pm 0.4$ & $-8.9 \pm 0.3$ & $-5.4 \pm 1.0$ \\
\hline & & 293 & $3.1( \pm 0.9) 10^{9}$ & $-12.7 \pm 0.5$ & $-9.1 \pm 0.5$ & $-3.6 \pm 0.8$ \\
\hline & & 298 & $3.6( \pm 0.4) 10^{8}$ & $-11.7 \pm 0.4$ & $-9.7 \pm 0.6$ & $-2.0 \pm 0.6$ \\
\hline & & 303 & $5.5( \pm 0.6) 10^{7}$ & $-10.7 \pm 0.4$ & $-9.7 \pm 0.6$ & $-1.0 \pm 0.4$ \\
\hline & & 308 & $2.8( \pm 0.8) 10^{6}$ & $-9.1 \pm 0.3$ & $-10.1 \pm 0.4$ & $1.0 \pm 0.4$ \\
\hline \multirow{5}{*}{$\mathrm{Cu}^{2+}$} & \multirow{5}{*}{$\begin{array}{c}\text { Apo-CA } \\
\text { (Active site) }\end{array}$} & 288 & $6.0( \pm 1.0) 10^{5}$ & $-7.6 \pm 0.6$ & $-6.1 \pm 0.3$ & $-1.5 \pm 0.4$ \\
\hline & & 293 & $4.7( \pm 0.3) 10^{5}$ & $-7.6 \pm 0.5$ & $-7.1 \pm 0.4$ & $-0.5 \pm 0.5$ \\
\hline & & 298 & $3.3( \pm 0.7) 10^{5}$ & $-7.5 \pm 0.6$ & $-9.0 \pm 0.5$ & $1.5 \pm 0.4$ \\
\hline & & 303 & $3.0( \pm 0.6) 10^{5}$ & $-7.6 \pm 0.4$ & $-9.9 \pm 0.5$ & $2.3 \pm 0.3$ \\
\hline & & 308 & $2.8( \pm 0.9) 10^{6}$ & $-9.1 \pm 0.2$ & $-11.1 \pm 0.5$ & $2.0 \pm 0.3$ \\
\hline \multirow{5}{*}{$\mathrm{Cu}^{2+}$} & & 288 & $2.0( \pm 0.7) 10^{9}$ & $-13.6 \pm 0.5$ & $-9.4 \pm 0.3$ & $-4.2 \pm 0.5$ \\
\hline & & 293 & $1.3( \pm 1.1) 10^{8}$ & $-12.2 \pm 0.4$ & $-9.6 \pm 0.6$ & $-2.6 \pm 0.6$ \\
\hline & $\mathrm{Zn}-\mathrm{CA}$ & 298 & $2.4( \pm 0.9) 10^{7}$ & $-11.4 \pm 0.4$ & $-9.8 \pm 0.6$ & $-1.6 \pm 0.6$ \\
\hline & (N-terminal & 303 & $1.9( \pm 0.9) 10^{6}$ & $-10.1 \pm 0.2$ & $-10.0 \pm 0.4$ & $-0.1 \pm 0.4$ \\
\hline & site) & 308 & $9.1( \pm 0.6) 10^{5}$ & $-9.8 \pm 0.3$ & $-10.1 \pm 0.3$ & $0.3 \pm 0.2$ \\
\hline
\end{tabular}


Table S2. Calculated $\Re^{\text {th }}$ values

\begin{tabular}{|c|c|c|c|c|c|}
\hline Titrant & Protein & $\begin{array}{c}\text { Temp } \\
(\mathrm{K})\end{array}$ & $\begin{array}{c}\Delta S \\
\left(\text { cal mol-1 } \mathrm{K}^{-1}\right)\end{array}$ & $\begin{array}{c}\Delta \mathrm{CP}_{\mathrm{P}} \\
\left(\mathrm{kcal} \mathrm{mol}^{-1} \mathrm{~K}^{-1}\right)\end{array}$ & $\mathfrak{R}^{\text {th }}$ \\
\hline \multirow{5}{*}{$\mathrm{Zn}^{2+}$} & \multirow{5}{*}{$\begin{array}{c}\text { Apo-CA } \\
\text { (Active site) }\end{array}$} & 288 & $3.1 \pm 1.4$ & $-0.22 \pm 0.02$ & 6 \\
\hline & & 293 & $-1.0 \pm 1.4$ & & 6 \\
\hline & & 298 & $-5.7 \pm 1.0$ & & 6 \\
\hline & & 303 & $-5.6 \pm 0.7$ & & 5 \\
\hline & & 308 & $-7.5 \pm 1.0$ & & 5 \\
\hline \multirow{5}{*}{$\mathrm{Cu}^{2+}$} & \multirow{5}{*}{$\begin{array}{c}\text { Zn-CA } \\
\text { (N-terminal site) }\end{array}$} & 288 & $15 \pm 2$ & $-0.04 \pm 0.01$ & -10 \\
\hline & & 293 & $9 \pm 2$ & & -8 \\
\hline & & 298 & $5 \pm 2$ & & -8 \\
\hline & & 303 & $0.3 \pm 1.3$ & & -7 \\
\hline & & 308 & $-1.0 \pm 0.6$ & & -7 \\
\hline \multirow{5}{*}{$\mathrm{Cu}^{2+}$} & \multirow{5}{*}{$\begin{array}{c}\text { Apo-CA } \\
\text { (Active site) }\end{array}$} & 288 & $5 \pm 1$ & $-0.26 \pm 0.02$ & 8 \\
\hline & & 293 & $2 \pm 2$ & & 8 \\
\hline & & 298 & $-5.0 \pm 1.3$ & & 8 \\
\hline & & 303 & $-7.6 \pm 1.0$ & & 8 \\
\hline & & 308 & $-6.5 \pm 1.0$ & & 7 \\
\hline \multirow{5}{*}{$\mathrm{Cu}^{2+}$} & \multirow{5}{*}{$\begin{array}{c}\text { Cu-CA } \\
\text { (N-terminal site) }\end{array}$} & 288 & $19 \pm 3$ & $-0.06 \pm 0.01$ & -9 \\
\hline & & 293 & $12 \pm 3$ & & -8 \\
\hline & & 298 & $7 \pm 2$ & & -7 \\
\hline & & 303 & $3.3 \pm 1.3$ & & -6 \\
\hline & & 308 & $-3.2 \pm 1.3$ & & -5 \\
\hline
\end{tabular}


Table S3. Apparent thermodynamic unfolding parameters for HCA.

\begin{tabular}{ccc}
\hline Species & $\boldsymbol{\Delta} \boldsymbol{G}_{\text {unf }}^{\boldsymbol{o}}\left(\mathbf{k c a l ~ \mathbf { ~ o l } ^ { - 1 } ) ^ { \star }}\right.$ & $\boldsymbol{m}\left(\mathbf{k c a l ~ m o l}^{-1} \mathbf{~ M}^{-1}\right)^{\star}$ \\
\hline Apo-HCA & $2.31 \pm 0.14$ & $2.48 \pm 0.09$ \\
Zn-HCA & $2.42 \pm 0.11$ & $2.33 \pm 0.08$ \\
CuZn-HCA & $1.97 \pm 0.16$ & $2.26 \pm 0.13$ \\
CuCu-HCA & $1.68 \pm 0.08$ & $1.75 \pm 0.04$ \\
\hline
\end{tabular}

* Uncertainties are given as the 95\% confidence interval of the mean, evaluated by 100 cycles of the non-parametric bootstrap method. ${ }^{8}$ This data is represented graphically, along with significance comparisons, in Figure S4. 


\section{Supporting Information References}

1. Song, H.; Wilson, D. L.; Farquhar, E. R.; Lewis, E. A.; Emerson, J. P. Revisiting Zinc Coordination in Human Carbonic Anhydrase II. Inorg. Chem. 2012, 51 (20), 1109811105.

2. Okrasa, K.; Kazlauskas, R. J. Manganese-Substituted Carbonic Anhydrase as a New Peroxidase. Chem. Eur. J. 2006, 12 (6), 1587-1596.

3. Nettles, W. L.; Song, H.; Farquhar, E. R.; Fitzkee, N. C.; Emerson, J. P. Characterization of the Copper(II) Binding Sites in Human Carbonic Anhydrase II. Inorg. Chem. 2015, 54 (12), 5671-5680.

4. Pace, C. N., Determination and Analysis of Urea and Guanidine Hydrochloride Denaturation Curves. In Methods Enzymol., Academic Press: 1986; Vol. 131, pp 266280.

5. Pace, C. N.; Shaw, K. L. Linear Extrapolation Method of Analyzing Solvent Denaturation Curves. Proteins: Struct. Funct. Bioinform. 2000, 41 (S4), 1-7.

6. Spolar, R. S.; Record, M. T. Coupling of Local Folding to Site-Specific Binding of Proteins to DNA. Science 1994, 263, 777-784.

7. Finkelstein, A. V.; Janin, J. The Price of Lost Freedom: Entropy of Bimolecular Complex Formation. Protein Eng. Des. Sel. 1989, 3 (1), 1-3.

8. Johnson, M. L., Outliers and Robust Parameter Estimation. In Methods Enzymol., Academic Press: 2000; Vol. 321, pp 417-424.

9. Håkansson, K.; Wehnert, A.; Liljas, A. X-Ray Analysis of Metal-Substituted Human Carbonic Anhydrase II Derivatives. Acta Crystallogr. Sect. D. Biol. Crystallogr. 1994, 50, 93-100.

10. Kim, J. K.; Lee, C.; Lim, S. W.; Adhikari, A.; Andring, J. T.; McKenna, R.; Ghim, C.-M.; Kim, C. U. Elucidating the Role of Metal lons in Carbonic Anhydrase Catalysis. Nat. Commun. 2020, 11 (1), 4557. 